\title{
A Unified Theory of Irresolute Multifunction
}

\author{
D. Sheeba ${ }^{1^{*}}$ and N. Nagaveni ${ }^{2}$ \\ ${ }^{1,2}$ Department of Mathematics, Coimbatore Institute of Technology, Coimbatore-14, Tamil Nadu, India
}

Available online at: www.isroset.org

Accepted 13/Aug/2018, Online 30/Aug/2018

\begin{abstract}
In this paper, A unified theory of irresolute multifunction such as an upper and lower $m_{w g}$-irresolute multifunction are studied and which is a generalisation of both irresolute multifunction and $\mathrm{m}$-irresolute multifunction. Also, we unified some of its characterizations in Minimal Structures.
\end{abstract}

AMS Subject Classification: 54C08, 54C60.

Key words: Upper / Lower $\mathrm{m}_{\mathrm{wg}}$-irresolute multifunction, $\mathrm{m}_{\mathrm{wg}}$ - normal space, $\mathrm{m}_{\mathrm{wg}}$-compact space, graph function and Minimal structures.

\section{INTRODUCTION}

In 1987, Popa [9] introduced irresolute multifunction and investigated some relation between continuous and irresolute multifunction in Topological spaces. In 1996, Cao et al., [1] introduced and studied weaker form of multifunction such as $\alpha$-continuous and $\alpha$ irresolute multifunction in topological space. In 2000, Noiri and Popa [6] introduced continuous multifunction in Minimal structures. Several authors introduced and studied various types of modifications of irresolute functions ([2], [3], [4] \& [7]). Nagaveni et al., [8] studied weakly generalized closed sets in Minimal structures.

In this paper, we introduced and studied some basic properties of generalisation of irresolute multifunction such as upper and lower $m_{w g}$-irresolute multifunction. In section II, we list some definitions, theorems and basic concepts of multifunctions. In section III, we defined as upper and lower $m_{w g}$-irresolute multifunction and we studied some of its characterizations with $m_{w g}$-Haussdroff space, $m_{w g}$ - normal space, $m_{w g}$-compact space, $m_{w g}$-connected space, $m_{w g^{-}}$ closed graph in Minimal Structures.

\section{PRELIMINARIES}

In this section, we list some definitions which are used in this sequel. We recall that, A multifunction $F: X \rightarrow Y$ is a point to set correspondence and we always assume that $F(x) \neq \Phi$ for every point $\mathrm{x} \in \mathrm{X}$. For a multifunction $F$, the upper and lower set $\mathrm{V}$ of $\mathrm{Y}$ will be denoted by $F^{+}(\mathrm{V})$ and $F^{-}(\mathrm{V})$ respectively, that is, $F^{+}(\mathrm{V})=\{\mathrm{x} \in \mathrm{X}: F(x) \subset \mathrm{V}\}$ and $F^{-}(\mathrm{V})=\{\mathrm{x} \in \mathrm{X}: F(x) \cap \mathrm{V} \neq \Phi\}$. In particular, $F^{-}(\mathrm{y})=\{\mathrm{x}$ $\in \mathrm{X}: y \in F(x)\}$ for each point $\mathrm{y} \in \mathrm{Y}$.

The graph multifunction $G_{F}:(X, \tau) \rightarrow(X \times Y, \tau \times$ $\sigma)$ of $F$ is defined by $G_{F}(x)=\{\{x\} \times F(x)\}$ for each $\mathrm{x} \in \mathrm{X}$.
Graph of $F$ (ie.) $\mathrm{G}(F)=\{(\mathrm{x}, \mathrm{y}) / \mathrm{x} \in \mathrm{X}, \mathrm{y} \in F(\mathrm{x})\}$. We say that $F$ has a closed graph if $\mathrm{G}(F)$ is closed in ( $\mathrm{X} \times \mathrm{Y}, \tau \times \alpha)$.

Throughout the paper $\left(\mathrm{X}, m_{X}\right)$ and $\left(\mathrm{Y}, m_{Y}\right)$ are denoted by minimal structure (briefly. $\mathrm{m}$-space). The interior and closure of a subset $\mathrm{A}$ of $\left(\mathrm{X}, m_{X}\right)$ are denoted by $m_{X}$ $\operatorname{Int}(\mathrm{A})$ and $m_{X}-\mathrm{Cl}(\mathrm{A})$ respectively.

Definition: 2.1 [6] Let $\mathrm{X}$ be a non empty set and $\mathrm{P}(\mathrm{X})$ the power set of $\mathrm{X}$. A subfamily $m_{X}$ of $\mathrm{P}(\mathrm{X})$ is called a minimal structure (briefly m-structure) on $\mathrm{X}$ if $\Phi \in m_{X}$ and $\mathrm{X} \in m_{X}$.

By $\left(X, m_{X}\right)$, we denote a nonempty set $X$ with an m-structure $m_{X}$ on $X$ and call it an m-space. Each member of $m_{X}$ is said to be $m_{X}$-open and the complement of an $m_{X}$ open set is said to be $m_{X}$-closed.

Definition: 2.2 [6] An m-structure $m_{X}$ on a nonempty set X is said to have property $B$ if the the union of any family of subsets belong to $m_{X}$ belongs to $m_{X}$.

Definition: 2.3 [6] Let $\mathrm{X}$ be a nonempty set and $m_{X}$ an mstructure on $\mathrm{X}$. For subset $\mathrm{A}$ of $\mathrm{X}$, the $m_{X}$-closure of $\mathrm{A}$ and the $m_{X}$-interior of $\mathrm{A}$ are defined in as follows:

i. $\quad m_{X}-\mathrm{Cl}(\mathrm{A})=\bigcap\left\{\mathrm{F}: \mathrm{A} \subset \mathrm{F}, \mathrm{X}-\mathrm{F} \in m_{X}\right\}$,

ii. $\quad m_{X}-\operatorname{Int}(\mathrm{A})=\mathrm{U}\left\{\mathrm{U}: \mathrm{U} \subset \mathrm{A}, \mathrm{U} \in m_{X}\right\}$.

Lemma: 2.4 [6] Let $\left(\mathrm{X}, m_{X}\right)$ be a space with minimal structure, let $\mathrm{A}$ be a subset of $\mathrm{X}$ and $\mathrm{x} \in \mathrm{X}$. Then $\mathrm{x} \in m_{X}$ $\mathrm{Cl}(\mathrm{A})$ if and only if $\mathrm{U} \cap \mathrm{A} \neq \Phi$, for every $\mathrm{U} \in m_{X}$ containing the point $\mathrm{x}$.

Definition: 2.5 [8] A subset A of a m-space $\left(\mathrm{X}, m_{X}\right)$ is said to be minimal weakly generalized closed (briefly. mwgclosed) sets if $m_{X}-\mathrm{Cl}\left(m_{X}-\operatorname{Int}(\mathrm{A})\right) \subset \mathrm{U}$ whenever $\mathrm{A} \subset \mathrm{U}$ and $\mathrm{U}$ is open in $m_{X}$. 
The complement of mwg-closed set is said to be mwg-open set. The family of all mwg-open (resp. mwg-closed) sets is denoted by $m_{X}-\mathrm{WGO}(\mathrm{X})$ (resp. $m_{X}-\mathrm{WGC}(\mathrm{X})$ ). We define, $m_{X}-\mathrm{WGO}(\mathrm{X}, \mathrm{x})=\left\{\mathrm{V} \in m_{X}-\mathrm{WGO}(\mathrm{X}) / \mathrm{x} \in \mathrm{V}\right\}$ for $\mathrm{x} \in$ $m_{X}$

Lemma: 2.6 [5] For a multifunction $F:\left(X, m_{X}\right) \rightarrow\left(Y, m_{Y}\right)$ following hold:

i. $G_{F}^{+}(A \times B)=A \cap F^{+}(B)$,

ii. $G_{F}^{-}(A \times B)=A \cap F^{-}(B)$, for any subsets $\mathrm{A} \subseteq \mathrm{X}$ and $\mathrm{B} \subseteq \mathrm{Y}$.

Definition: 2.7 [10] A $m_{w g}$ - frontier of a subset $\mathrm{A}$ of $\mathrm{X}$ is $m_{w g}-\mathrm{fr}(\mathrm{A})=m_{w g}-\mathrm{Cl}(\mathrm{A}) \cap m_{w g}-\mathrm{Cl}(\mathrm{X} \backslash \mathrm{A})$.

Definition: 2.8 [10] A m-space $\left(\mathrm{X}, m_{X}\right)$ is said to be

i. $\quad m_{w g}$-Frechet space (i.e. $m_{w g}-\mathrm{T}_{1}$ space) if for every pair of distinct points $\mathrm{x}, \mathrm{y}$ in $\mathrm{X}$ there exists a wgopen set $\mathrm{U} \subset \mathrm{X}$ containing $\mathrm{x}$ but not $\mathrm{y}$ and a wgopen set $\mathrm{V} \subset \mathrm{X}$ containing $\mathrm{y}$ but not $\mathrm{X}$.

ii. $\quad m_{w g}$-Haussdroff space (i.e. $m_{w g}-\mathrm{T}_{2}$ space) if for every pair of distinct points $\mathrm{x}, \mathrm{y}$ in $\mathrm{X}$ there exists disjoint mwg-open sets $U \in X$ and $V \in X$ containing $\mathrm{x}$ and $\mathrm{y}$ respectively.

iii. mwg-normal if for each pair of non empty disjoint m-closed sets can be separated by disjoint mwgopen sets.

iv. $\quad m_{w g}$-compact if every wg-open cover of $\mathrm{X}$ admits a finite subcover.

v. $m_{w g}$ - connected if it cannot be written as the union of two nonempty disjoint mwg-open sets.

Definition: 2.9 [10] A function $\mathrm{f}:\left(\mathrm{X}, m_{X}\right) \rightarrow\left(\mathrm{Y}, m_{Y}\right)$ is said to be minimal weakly generalized closed graph (briefly. $m_{w g}$ - closed graph) if for each $(\mathrm{x}, \mathrm{y}) \in(\mathrm{X} \times \mathrm{Y})-\mathrm{G}(\mathrm{f})$, there exist $\mathrm{U} \in m_{w g}-\mathrm{WGO}(\mathrm{X}, \mathrm{x})$ and $\mathrm{V} \in m_{w g}-\mathrm{WGO}(\mathrm{Y}, \mathrm{y})$ such that $(\mathrm{U} \times \mathrm{V}) \cap \mathrm{G}(\mathrm{f})=\Phi$.

Lemma: 2.10 [10] A function $\mathrm{f}:\left(\mathrm{X}, m_{X}\right) \rightarrow\left(\mathrm{Y}, m_{Y}\right)$ is said to be $m_{w g}$-closed graph if for each $(\mathrm{x}, \mathrm{y}) \in(\mathrm{X} \times \mathrm{Y})-\mathrm{G}(\mathrm{f})$, there exist $\mathrm{U} \in m_{X}-\mathrm{WGO}(\mathrm{X}, \mathrm{x})$ and $\mathrm{V} \in m_{Y}-\mathrm{WGO}(\mathrm{Y}, \mathrm{y})$ such that $\mathrm{f}(\mathrm{U}) \cap \mathrm{V}=\Phi$.

Definition: 2.11 [11] A multifunction $F:\left(X, m_{X}\right) \rightarrow$ $\left(Y, m_{Y}\right)$ is called

i. upper $m_{w g}$-continuous (briefly, u. $m_{w g}$-c.) at a point $\mathrm{x} \in \mathrm{X}$ if for each $\mathrm{m}$-open subset $\mathrm{V}$ of $\mathrm{Y}$ with $F(x) \subseteq \mathrm{V}$, there is an mwg-open set $\mathrm{U}$ containing x such that $F(U) \subseteq \mathrm{V}$.

ii. lower $m_{w g}$-continuous (briefly, $1 . m_{w g}$-c) at a point $\mathrm{x} \in \mathrm{X}$ if for each m-open subset $\mathrm{V}$ of $\mathrm{Y}$ with $F(x)$ $\cap \mathrm{V} \neq \Phi$, there is an mwg-open set $\mathrm{U}$ containing $\mathrm{x}$ such that $F(y) \cap \mathrm{V} \neq \Phi$, for every point y $\in \mathrm{U}$.

\section{UPPER AND LOWER $m_{w g}$-IRRESOLUTE MULTIFUNCTIONS}

In this Section, we introduced and studied upper / lower $m_{w g}$-irresolute multifunction and also we characterize these multifunctions with graph functions and some new spaces.

Definition: 3.1 A multifunction $F:\left(X, m_{X}\right) \rightarrow\left(Y, m_{Y}\right)$ is called

i. upper $m_{w g}$-irresolute (briefly, u. $m_{w g}$-i) at a point $\mathrm{x}$ $\in \mathrm{X}$ if for each mwg-open subset $\mathrm{V}$ of $m_{Y}$ with $F(x) \subseteq \mathrm{V}$, there is an mwg-open set $\mathrm{U}$ containing x such that $F(U) \subseteq \mathrm{V}$.

ii. lower $m_{w g}$ - irresolute (briefly, $1 . m_{w g}$-i) at a point $\mathrm{x} \in \mathrm{X}$ if for each mwg-open subset $\mathrm{V}$ of $m_{Y}$ with $F(x) \cap \mathrm{V} \neq \Phi$, there is an mwg-open set $\mathrm{U}$ containing $\mathrm{x}$ such that $F(y) \cap \mathrm{V} \neq \Phi$, for every point $\mathrm{y} \in \mathrm{U}$.

iii. Upper $m_{w g}$-irresolute (Lower $m_{w g}$-irresolute) if $F$ has this property at every point $\mathrm{x} \in \mathrm{X}$.

Remark: 3.2 From the following examples, it is clear that upper $m_{w g}$-irresolute and lower $m_{w g}$-irresolute are independent of each other.

Example: 3.3 Let $\mathrm{X}=\{-1,0,1,2\}$ and $\mathrm{Y}=\{\mathrm{a}, \mathrm{b}, \mathrm{c}\}$ be endowed with the minimal structures $m_{X}=\{X, \Phi,\{-1,0\}$, $\{0,1,2\}\}$ and $m_{Y}=\{\mathrm{Y}, \Phi,\{\mathrm{b}, \mathrm{c}\}\}$. If multifunction $F:\left(X, m_{X}\right) \rightarrow\left(Y, m_{Y}\right)$ is defined by $F(x)=\left\{\begin{array}{cl}\{a\}, & \text { if } x=-1 \\ \{a, b\}, & \text { if } x=0 \\ \{c\}, & \text { if } x=1 \\ \{a, b, c\}, & \text { if } x=2\end{array}\right.$. Then $\mathrm{F}$ is upper $m_{w g}$-irresolute, but it is not lower $m_{w g}$-irresolute. Since $\{c\}$ is mwg-open in $m_{Y}$, but $F^{-}(\{c\})=\{1,2\}$ is not mwg-open in $m_{X}$.

Example: 3.4 Let X, Y, $m_{X}$ and $m_{Y}$ be as in previous Example. If multifunction $F:\left(X, m_{X}\right) \rightarrow\left(Y, m_{Y}\right)$ is defined by $F(x)=\left\{\begin{array}{ll}\{c\}, & \text { if } x=-1 \\ \{b\}, & \text { if } x=0 \\ \{a\}, & \text { if } x=1 \\ \{a, b, c\}, & \text { if } x=2\end{array}\right.$. Then F is lower $m_{w g}$-irresolute, but it is not upper $m_{w g}$-irresolute. Since $\{c\}$ is mwg-open in $m_{Y}$, but $F^{+}(\{c\})=\{-1\}$ is not mwg-open in $m_{X}$.

Remark: 3.5 From the following examples, it is clear that upper $m_{w g}$-irresolute and lower $m_{w g}$-irresolute is upper $m_{w g}$-continuous and lower $m_{w g}$-continuous respectively. But the converse need not be true.

Example: 3.6 Let $\mathrm{X}=\{\mathrm{a}, \mathrm{b}, \mathrm{c}\}$ and $\mathrm{Y}=\{\mathrm{p}, \mathrm{q}, \mathrm{r}\}$ be endowed with the minimal structures $m_{X}=\{\mathrm{X}, \Phi,\{\mathrm{a}, \mathrm{b}\}\}$ 
and $m_{Y}=\{\mathrm{Y}, \Phi, \quad\{\mathrm{p}\}, \quad\{\mathrm{q}, \mathrm{r}\}\}$. If multifunction $F:\left(X, m_{X}\right) \rightarrow\left(Y, m_{Y}\right)$ is defined by $F(x)=\left\{\begin{array}{l}\{p\}, \text { if } x=a \\ \{q\}, \text { if } x=b . \\ \{r\}, \text { if } x=c\end{array}\right.$.

Then $\mathrm{F}$ is upper $m_{w g}$-continuous, but it is not upper $m_{w g^{-}}$ irresolute. Since $\{r\}$ is mwg-open in $m_{Y}$, but $F^{+}(\{r\})=\{c\}$ is not mwg-open in $m_{X}$.

Example: 3.7 Let $\mathrm{X}=\{\mathrm{a}, \mathrm{b}, \mathrm{c}, \mathrm{d}\}$ and $\mathrm{Y}=\{\mathrm{P}, \mathrm{q}, \mathrm{r}, \mathrm{s}\}$ endowed with the minimal structures $m_{X}=\{X, \Phi,\{a\},\{a$, $\mathrm{b}\},\{\mathrm{a}, \mathrm{b}, \mathrm{c}\}\}$ and $m_{Y}=\{\mathrm{Y}, \Phi,\{\mathrm{p}, \mathrm{q}, \mathrm{r}\}\}$. If multifunction $F:\left(X, m_{X}\right) \rightarrow\left(Y, m_{Y}\right)$ is defined by $F(x)=\left\{\begin{array}{lll}\{p, q\}, & \text { if } x=a \\ \{q, r, s\}, & \text { if } x=b \\ \{r\}, & \text { if } x=c \\ \{s\}, & \text { if } x=d\end{array}\right.$. Then $F$ is lower $m_{w g}$-continuous, but it is not lower $m_{w g}$-irresolute. Since $\{r, s\}$ is mwg-open in $m_{Y}$, but $F^{-}(\{r, s\})=\{b, c, d\}$ is not mwg-open in $m_{X}$.

Definition: 3.8 Let $\mathrm{X}$ be a nonempty set and $m_{X}$ an $\mathrm{m}$ structure on $\mathrm{X}$. For subset $\mathrm{A}$ of $\mathrm{X}$, the $m_{X}$-closure of $\mathrm{A}$ and the $m_{X}$-interior of $\mathrm{A}$ are defined in as follows:
1) $m_{w g}-C l(A)=\bigcap\left\{\mathrm{F}: \mathrm{A} \subset \mathrm{F}, \mathrm{X}-\mathrm{F} \in m_{X}-\right.$ $\mathrm{WGC}(\mathrm{X})\}$,
2) $m_{w g}-\operatorname{Int}(A)=\mathrm{U}\left\{\mathrm{U}: \mathrm{U} \subset \mathrm{A}, \mathrm{U} \in m_{X}-\right.$ $\operatorname{WGO}(\mathrm{X})\}$.

Theorem: 3.9 The following are equivalent for a multifunction $F:\left(X, m_{X}\right) \rightarrow\left(Y, m_{Y}\right)$.

1) $F$ is lower $m_{w g}$-irresolute.

2) For each $x \in X$ and for each mwg-open set $V$ with $\mathrm{F}(\mathrm{x}) \cap \mathrm{V} \neq \Phi$, there exist a $\mathrm{U} \in m_{X}-\mathrm{WGO}(\mathrm{X})$ such that if $\mathrm{y} \in \mathrm{U}$, then $F(y) \cap V \neq \Phi$,

3) $F^{-}(\mathrm{V}) \in m_{X}-\mathrm{WGO}(\mathrm{X})$ for any mwg-open set $\mathrm{V}$ $\subset m_{Y}$,

4) $F^{+}(\mathrm{V}) \in m_{X}-\mathrm{WGC}(\mathrm{X})$ for any mwg-closed set $\mathrm{K}$ $\subset m_{Y}$,

5) $m_{w g}-C l\left(F^{+}(\mathrm{B})\right) \subset F^{+}\left(m_{w g}-C l(\mathrm{~B})\right)$ for every subset B of Y,

6) $F^{-}\left(m_{w g}-\operatorname{Int}(B)\right) \subset m_{w g}-\operatorname{Int}\left(F^{-}(B)\right)$ for every subset B of Y,

7) $m_{X}-C l\left(m_{w g}-\operatorname{Int}\left(F^{+}(\mathrm{B})\right)\right) \subset F^{+}\left(m_{w g}-C l(\mathrm{~B})\right)$ for every subset B of $\mathrm{Y}$,

8) $\quad F\left(m_{X}-C l\left(m_{w g}-\operatorname{Int}(A)\right)\right) \subset m_{w g}-C l(\mathrm{~F}(\mathrm{~A}))$ for every subset A of $\mathrm{X}$,

9) $F\left(m_{w g}-C l(\mathrm{~A})\right) \subset m_{w g}-C l(\mathrm{~F}(\mathrm{~A}))$ for every subset A of X.

Proof: 1$) \Leftrightarrow 2$ ). This is obvious.

1) $\Rightarrow 3$ ). Let $x \in X$ and $G$ be a mwg-open set of $m_{Y}$ such that $\mathrm{x} \in F^{-}(G)$. By 1 , there exists a $U_{x} \in m_{X}-W G O(X, x)$ such that $U_{x} \subset F^{-}(G)$. Therefore, we have $F^{-}(G)=$ $\bigcup_{x \in F^{-}(G)} U_{x}$ and hence $F^{-}(G) \in m_{X}-W G O(X, x)$.
3) $\Rightarrow 1)$. Let $\mathrm{V} \in m_{Y}-W G O(Y)$ and $\mathrm{x} \in F^{-}(V)$. By 3 , $F^{-}(V) \in m_{X}-W G O(X, x)$. Take $\mathrm{U}=F^{-}(V)$. We obtain $\mathrm{U}$ $\subseteq F^{-}(V)$.

$3) \Leftrightarrow 4)$. Let $\mathrm{K}$ be any mwg-closed set in $m_{Y}$. Then, $\mathrm{Y} \backslash \mathrm{K}$ is an mwg-open set of $\mathrm{Y}$. By $3, F^{-}(\mathrm{Y} \backslash \mathrm{K}) \in m_{X}-W G O(X, x)$. Since $F^{-}(\mathrm{Y} \backslash \mathrm{K})=\mathrm{X} \backslash F^{+}(\mathrm{K})$, we obtain that $F^{+}(\mathrm{K})$ is mwgclosed in $\mathrm{X}$.

$4) \Rightarrow 5)$. For any subset B of Y, $m_{w g}-C l(\mathrm{~B})$ is mwg-closed in $\mathrm{Y}$ and then $F^{+}\left(m_{w g}-C l(\mathrm{~B})\right)$ is mwg-closed in $\mathrm{X}$. Hence $m_{w g}-C l\left(F^{+}(\mathrm{B})\right) \subset F^{+}\left(m_{w g}-C l(\mathrm{~B})\right)$.

$5) \Rightarrow 4)$. Let $\mathrm{K}$ be any mwg-closed set in $\mathrm{Y}$. Then $m_{w g}$ $C l\left(F^{+}(\mathrm{K})\right) \subset F^{+}\left(m_{w g}-C l(\mathrm{~K})\right)=F^{+}(\mathrm{K})$ and hence $F^{+}(\mathrm{K})$ is a mwg-closed set in $\mathrm{X}$.

$3) \Rightarrow 6)$. For any subset B of $\mathrm{Y}, m_{w g}-\operatorname{Int}(B)$ is mwg-open in $\mathrm{Y}$ and then $F^{-}\left(m_{w g}-\operatorname{Int}(B)\right)$ is mwg-open in $\mathrm{X}$. Hence $F^{-}\left(m_{w g}-\operatorname{Int}(B)\right) \subset m_{w g}-\operatorname{Int}\left(F^{-}(B)\right)$.

$6) \Rightarrow 3)$. Let $\mathrm{V}$ be any mwg-open set of Y. Then $F^{-}(V)=$ $F^{-}\left(m_{w g}-\operatorname{Int}(V)\right) \subset m_{w g}-\operatorname{Int}\left(F^{-}(V)\right)$ and hence $F^{-}(V) \in m_{X}-W G O(X, x)$.

$4) \Rightarrow 7)$. Let B be any subset of Y. Since $m_{w g}-C l(\mathrm{~B})$ is mwg-closed, $F^{+}\left(m_{w g}-C l(\mathrm{~B})\right)$ is mwg-closed in $\mathrm{X}$ and $F^{+}(\mathrm{B}) \subset F^{+}\left(m_{w g}-C l(\mathrm{~B})\right)$. Therefore, we obtain $m_{w g}-$ $C l\left(F^{+}(\mathrm{B})\right) \subset F^{+}\left(m_{w g}-C l(\mathrm{~B})\right)$ and hence $m_{X}-C l\left(m_{Y}-\right.$ $\operatorname{Int}\left(F^{+}(B)\right) \subset m_{X}-\operatorname{Cl}\left(m_{Y}-\operatorname{Int}\left(F^{+}\left(m_{w g}-C l(B)\right)\right)\right) \subset$ $F^{+}\left(m_{w g}-C l(\mathrm{~B})\right)$.

$7) \Rightarrow 8)$. Let A be any subset of $X$. By 7, we have $m_{X}-$ $C l\left(m_{Y}-\operatorname{Int}(A) \subset m_{X}-\operatorname{Cl}\left(m_{Y}-\operatorname{Int}\left(F^{+}(F(A))\right)\right) \subset\right.$ $F^{+}\left(m_{w g}-C l(\mathrm{~F}(\mathrm{~A}))\right)$. Therefore, we obtain $F\left(m_{X}-\right.$ $\left.C l\left(m_{X}-\operatorname{Int}(A)\right)\right) \subset m_{w g}-(F(A))$.

$8) \Rightarrow 9)$. Let $A$ be any subset of $X$. By the previous proposition and by $8, F\left(m_{w g}-C l(A)\right)=F\left(A \cup m_{X}-\right.$ $\left.C l\left(m_{X}-\operatorname{Int}(A)\right)\right) \subset m_{w g}-\operatorname{Cl}(F(A))$.

$9) \Rightarrow 5)$. Let B be any subset of Y. Then, we have $F\left(m_{w g}-\right.$ $\left.C l\left(F^{+}(\mathrm{B})\right)\right) \subset m_{w g}-C l\left(F\left(F^{+}(\mathrm{B})\right)\right)$ and hence $m_{w g}-$ $C l\left(F^{+}(\mathrm{B})\right) \subset F^{+}\left(m_{w g}-C l\left(F\left(F^{+}(\mathrm{B})\right)\right) \subset F^{+}\left(m_{w g}-\right.\right.$ $C l(B))$.

Theorem: 3.10 The following are equivalent for a multifunction $F:\left(X, m_{X}\right) \rightarrow\left(Y, m_{Y}\right)$.

1) $F$ is upper $m_{w g}$-irresolute.

2) For each $x \in X$ and for each mwg-open set $V$ such that $\mathrm{F}(\mathrm{x}) \subset \mathrm{V}$, there exist a $\mathrm{U} \in m_{X}-\mathrm{WGO}(\mathrm{X})$ such that if $\mathrm{y} \in \mathrm{U}$, then $F(y) \subset V$,

3) $F^{+}(\mathrm{V}) \in m_{X}-\mathrm{WGO}(\mathrm{X})$ for any mwg-open set $\mathrm{V}$ $\subset m_{Y}$,

4) $F^{-}(\mathrm{V}) \in m_{X}-\mathrm{WGC}(\mathrm{X})$ for any mwg-closed set $\mathrm{K}$ $\subset m_{Y}$,

5) $m_{w g}-C l\left(F^{-}(\mathrm{B})\right) \subset F^{-}\left(m_{w g}-C l(\mathrm{~B})\right)$ for every subset B of $\mathrm{Y}$,

6) $F^{+}\left(m_{w g}-\operatorname{Int}(B)\right) \subset m_{w g}-\operatorname{Int}\left(F^{+}(B)\right)$ for every subset $\mathrm{B}$ of $\mathrm{Y}$, 
7) $m_{X}-C l\left(m_{w g}-\operatorname{Int}\left(F^{-}(\mathrm{B})\right)\right) \subset F^{-}\left(m_{w g}-C l(\mathrm{~B})\right)$ for every subset $\mathrm{B}$ of $\mathrm{Y}$,

Proof: It can be obtained as the previous theorem.

Theorem: 3.11 If $F:\left(X, m_{X}\right) \rightarrow\left(Y, m_{Y}\right)$ is an upper $m_{w g^{-}}$ irresolute injection and $\mathrm{Y}$ is mwg- $\mathrm{T}_{1}$, then $\mathrm{X}$ is $\mathrm{mwg}-\mathrm{T}_{1}$.

Proof: Assume that $\mathrm{Y}$ is $\mathrm{mwg}^{-\mathrm{T}_{1}}$. For any distinct points $\mathrm{x}$ and $\mathrm{y}$ in $\mathrm{X}$, there exists mwg-open set $\mathrm{A}$ and $\mathrm{W}$ such that $\mathrm{F}(\mathrm{x}) \in \mathrm{A}, \mathrm{F}(\mathrm{y}) \notin \mathrm{A}, \mathrm{F}(\mathrm{x}) \notin \mathrm{W}$ and $\mathrm{F}(\mathrm{y}) \in \mathrm{W}$. Since $\mathrm{F}$ is upper $m_{w g}$-irresolute, there exists mwg-open sets $\mathrm{U}$ and $\mathrm{V}$ such that $\mathrm{x} \in \mathrm{U}, \mathrm{y} \in \mathrm{V}, \mathrm{F}(\mathrm{U}) \subseteq \mathrm{A}$ and $\mathrm{F}(\mathrm{V}) \subseteq \mathrm{W}$. Thus we obtain $\mathrm{y} \notin \mathrm{U}, \mathrm{x} \notin \mathrm{V}$. This shows that $\mathrm{X}$ is mwg- $\mathrm{T}_{1}$.

Theorem: 3.12 If $F:\left(X, m_{X}\right) \rightarrow\left(Y, m_{Y}\right)$ is an upper $m_{w g^{-}}$ irresolute injection and $\mathrm{Y}$ is $m_{w g}$-Haussdroff space, then $\mathrm{X}$ is $m_{w g}$-Haussdroff space.

Proof: For any distinct points $\mathrm{x}$ and $\mathrm{y}$ in $\mathrm{X}$, there exists mwg-open set $\mathrm{U}$ and $\mathrm{V}$ such that $\mathrm{F}(\mathrm{x}) \in \mathrm{U}$ and $\mathrm{F}(\mathrm{y}) \in \mathrm{V}$. Since $\mathrm{F}$ is upper $m_{w g}$-irresolute, there exists mwg-open sets $\mathrm{P}$ and $\mathrm{Q}$ such that $\mathrm{x} \in \mathrm{P}, \mathrm{y} \in \mathrm{Q}, \mathrm{F}(\mathrm{P}) \subseteq \mathrm{U}$ and $\mathrm{F}(\mathrm{Q}) \subseteq \mathrm{V}$. Since $\mathrm{P}$ and $\mathrm{Q}$ are disjoint, we have $\mathrm{U} \cap \mathrm{V}=\Phi$, hence $\mathrm{P} \cap$ $\mathrm{Q}=\Phi$. This shows that $\mathrm{X}$ is $m_{w g}$-Haussdroff space.

Theorem: 3.13 If $F:\left(X, m_{X}\right) \rightarrow\left(Y, m_{Y}\right)$ is upper $m_{w g^{-}}$ irresolute, injective multifunction and from a minimal space $\mathrm{X}$ to a $m_{w g}$ - normal space $\mathrm{Y}$, then $\mathrm{X}$ is a $m_{w g}$-Haussdroff space.

Proof: Let $\mathrm{x}$ and $\mathrm{y}$ be any two distinct points in X. Then we have $F(x) \cap F(y)=\Phi$ since $\mathrm{F}$ is injective. Since $\mathrm{Y}$ is $m_{w g^{-}}$ normal space, it follows that there exist disjoint m-open sets $\mathrm{U}$ and $\mathrm{V}$ containing $F(\mathrm{x})$ and $F(\mathrm{y})$, respectively. Thus, there exist disjoint mwg-open sets $\mathrm{F}^{+}(\mathrm{U})$ and $\mathrm{F}^{+}(\mathrm{V})$ containing $\mathrm{x}$ and $\mathrm{y}$, respectively such $\mathrm{G} \subset \mathrm{F}^{+}(\mathrm{U})$ and $\mathrm{W} \subset \mathrm{F}^{+}(\mathrm{V})$. Therefore, we obtain $\mathrm{G} \cap \mathrm{W}=\Phi$. Hence $\mathrm{X}$ is $m_{w g^{-}}$ Haussdroff space.

Theorem: 3.14 Let $F:\left(X, m_{X}\right) \rightarrow\left(Y, m_{Y}\right)$ be a multifunction. An upper $m_{w g}$-irresolute image of a $m_{w g^{-}}$ connected space is $m_{w g}$-connected for a multifunction.

Proof: Let $F:\left(X, m_{X}\right) \rightarrow\left(Y, m_{Y}\right)$ be an upper $m_{w g^{-}}$ irresolute from a $m_{w g}$-connected space $X$ onto a $m_{w g}$ connected space $\mathrm{Y}$. Suppose $\mathrm{Y}$ is not $m_{w g}$-connected and let $\mathrm{Y}=\mathrm{U} U \mathrm{~V}$ be a partition of $\mathrm{Y}$. Then both $\mathrm{U}$ and $\mathrm{V}$ are mwg-open and mwg-closed subset of $Y$. Since $F$ is an upper $m_{w g}$-irresolute, $\mathrm{F}^{+}(\mathrm{U})$ and $\mathrm{F}^{+}(\mathrm{V})$ are mwg-open subset of $\mathrm{X}$. In view of the fact that $\mathrm{F}^{+}(\mathrm{U})$ and $\mathrm{F}^{+}(\mathrm{V})$ are disjoint, $\mathrm{X}$ $=\mathrm{F}^{+}(\mathrm{U}) \cup \mathrm{F}^{+}(\mathrm{V})$ is a partition of $\mathrm{X}$. This is contrary to the connectedness of $\mathrm{X}$.

Theorem: 3.15 Let $F:\left(X, m_{X}\right) \rightarrow\left(Y, m_{Y}\right)$ be a multifunction. If the graph function $G_{F}: \mathrm{X} \rightarrow X \times Y$ is upper $m_{w g}$-irresolute, then $F$ is upper $m_{w g}$-irresolute.
Proof: Suppose that $G_{F}$ is upper $m_{w g}$-irresolute. Let $\mathrm{x} \in \mathrm{X}$ and $\mathrm{W}$ be any mwg-open set of $m_{Y}$ such that $F(\mathrm{x}) \subset \mathrm{V}$. Then $G_{F}(x) \subset(\mathrm{X} \times \mathrm{V})$ and $X \times V$ is mwg-open set in $X \times Y$. Since $G_{F}$ is upper $m_{w g}$-irresolute, there is an mwg-open set $\mathrm{U}$ with $\mathrm{x} \in \mathrm{U}$ such that $G_{F}(U) \subset X \times V$. By Lemma 2.6, $\mathrm{U} \subset$ $G_{F}^{+}(X \times V)=\mathrm{X} \cap F^{+}(\mathrm{V})=F^{+}(\mathrm{V})$ and $F(\mathrm{U}) \subset \mathrm{V}$. So $F$ is upper $m_{w g}$-irresolute at $\mathrm{x} \in \mathrm{X}$. The proof of the lower $m_{w g^{-}}$ irresolute $F$ can be done using a similar argument.

Theorem: 3.16 Let $F:\left(X, m_{X}\right) \rightarrow\left(Y, m_{Y}\right)$ be a multifunction. If the graph function $G_{F}: \mathrm{X} \rightarrow X \times Y$ is lower $m_{w g}$-irresolute, then $F$ is lower $m_{w g}$-irresolute.

Proof: Suppose that $G_{F}$ is lower $m_{w g}$-irresolute. Let $\mathrm{x} \in \mathrm{X}$ and $\mathrm{V}$ be any mwg-open set of $\mathrm{Y}$ such that $\mathrm{x} \in F^{-}(\mathrm{V})$. Then $\mathrm{X} \times \mathrm{V}$ is mwg-open in $\mathrm{X} \times \mathrm{Y}$ and $G_{F}(x) \cap(\mathrm{X} \times \mathrm{V})=(\{\mathrm{x}\}$ $\times(F(\mathrm{x}) \cap \mathrm{V})) \neq \Phi$. Since $G_{F}$ is lower $m_{w g}$-irresolute, there exists a mwg-open set $\mathrm{U}$ containing $\mathrm{x}$ such that $\mathrm{U} \subset$ $G_{F}^{-}(X \times V)$. By Lemma 2.6, we have $\mathrm{U} \subset F^{-}(\mathrm{V})$. This shows that $F$ is lower $m_{w g}$-irresolute.

Theorem: 3.17 If $F:\left(X, m_{X}\right) \rightarrow\left(Y, m_{Y}\right)$ is upper $m_{w g^{-}}$ irresolute multifunction, and $\mathrm{Y}$ is $m_{w g}$-Haussdroff space, then the graph of function $G(F)$ is $m_{w g}$-closed graph.

Proof: Suppose that $(\mathrm{x}, \mathrm{y}) \notin \mathrm{G}(\mathrm{F})$, then $\mathrm{F}(\mathrm{x}) \neq \mathrm{y}$. Since $\mathrm{Y}$ is $m_{w g}$-Haussdroff space, there exists mwg-open sets $\mathrm{U}$ and $\mathrm{V}$ such that $\mathrm{F}(\mathrm{x}) \in \mathrm{U}, \mathrm{y} \in \mathrm{V}$ and $\mathrm{U} \cap \mathrm{V}=\Phi$. Since $\mathrm{F}$ is upper $m_{w g}$-irresolute, so by Definition, there exists a mwg-open set $\mathrm{W}$ in $\mathrm{X}$ containing $\mathrm{x}$ such that $\mathrm{F}(\mathrm{W}) \subseteq \mathrm{U}$. Hence, we have $\mathrm{F}(\mathrm{W}) \cap \mathrm{V}=\Phi$. This means that $\mathrm{G}(\mathrm{F})$ is $m_{w g}$-closed graph.

Theorem: 3.18 If $F:\left(X, m_{X}\right) \rightarrow\left(Y, m_{Y}\right)$ is upper $m_{w g^{-}}$ irresolute multifunction such that $F(\mathrm{x})$ is $m_{w g}$-compact for each $\mathrm{x} \in \mathrm{X}$ and $\mathrm{Y}$ is $m_{w g}$-Haussdroff space, then the graph of function $G(F)$ is $m_{w g}$-closed in $\mathrm{X} \times \mathrm{Y}$.

Proof: Let $(x, y) \notin G(F)$. That is $\mathrm{y} \notin F(\mathrm{x})$. Since $\mathrm{Y}$ is $m_{w g^{-}}$ Haussdroff space, for each $\mathrm{z} \in F(\mathrm{x})$, there exist disjoint mwg-open sets $\mathrm{V}(\mathrm{z})$ and $\mathrm{U}(\mathrm{z})$ of $\mathrm{Y}$ such that $\mathrm{z} \in \mathrm{U}(\mathrm{z})$ and $\mathrm{y}$ $\in \mathrm{V}(\mathrm{z})$. Then $\{\mathrm{U}(\mathrm{z}): \mathrm{z} \in \mathrm{F}(\mathrm{x})\}$ is mwg-open cover of $F(\mathrm{x})$ and since $F(\mathrm{x})$ is $m_{w g}$-compact, there exists a finite number of points , say, $\mathrm{z}_{1}, \mathrm{z}_{2}, \ldots \mathrm{z}_{\mathrm{n}}$ in $F(\mathrm{x})$ such that $F(\mathrm{x})$ $\subset \bigcup\left\{U\left(z_{i}\right): i=1,2,3, \ldots . n\right\}$. Put $\mathrm{U}=\bigcup\left\{U\left(z_{i}\right): i=\right.$ $1,2,3, \ldots . n\}$ and $\mathrm{V}=\bigcap\left\{V\left(z_{i}\right): i=1,2,3, \ldots . n\right\}$. Then Then $\mathrm{U}$ and $\mathrm{V}$ are mwg-open in $\mathrm{Y}$ such that $F(\mathrm{x}) \subset \mathrm{U}, \mathrm{y} \in \mathrm{V}$ and $\mathrm{U} \cap \mathrm{V}=\Phi$. Since $\mathrm{F}$ is upper $m_{w g}$-irresolute, there exists a mwg-open set A containing $\mathrm{x}$, such that $F(\mathrm{~A}) \subset \mathrm{U}$. Since V is mwg-open, it follows that $\mathrm{A} \times \mathrm{V} \in m_{X}-\mathrm{WGO}(\mathrm{X} \times \mathrm{Y})$ and $(\mathrm{x}, \mathrm{y}) \in \mathrm{A} \times \mathrm{V} \subset(\mathrm{X} \times \mathrm{Y})-\mathrm{G}(\mathrm{F})$. we obtain that $(\mathrm{X} \times \mathrm{Y})-$ $\mathrm{G}(\mathrm{F})=\mathrm{U}_{(\mathrm{X} \times \mathrm{Y})-\mathrm{G}(\mathrm{F})} A \times V$ is mwg-open set in $\mathrm{X} \times \mathrm{Y}$ and hence $G(F)$ is $m_{w g}$-closed in $\mathrm{X} \times \mathrm{Y}$.

Theorem: 3.19 Let $F:\left(X, m_{X}\right) \rightarrow\left(Y, m_{Y}\right)$ be an upper $m_{w g}$-irresolute surjective multifunction such that $\mathrm{F}(\mathrm{x})$ is a 
$m_{w g}$-compact for each $\mathrm{x} \in \mathrm{X}$. If $\mathrm{X}$ is a $m_{w g}$-Compact space, then $\mathrm{Y}$ is a $m_{w g}$-compact.

Proof: Let $\left\{\mathrm{V}_{\mathrm{i}}: \mathrm{i} \in \mathrm{I}\right\}$ be a mwg-open cover of Y. Since $\mathrm{F}(\mathrm{x})$ is $m_{w g}$-compact for each $\mathrm{x} \in \mathrm{X}$, there exists a finite subset $\mathrm{I}(\mathrm{x})$ of $\mathrm{I}$ such that $F(x) \subset \mathrm{U}\left\{\mathrm{V}_{\mathrm{i}}: \mathrm{i} \in \mathrm{I}(\mathrm{x})\right\}$. Put $V(x) \subset$ $\mathrm{U}\left\{\mathrm{V}_{\mathrm{i}}: \mathrm{i} \in \mathrm{I}(\mathrm{x})\right\}$. Since $F$ is upper $m_{w g}$-irresolute, there exist a mwg-open set $U(x)$ of $X$ containing $x$ such that $F(U(x)) \subset$ $\mathrm{V}(\mathrm{x})$. Then the family $\{\mathrm{U}(\mathrm{x}): \mathrm{x} \in \mathrm{X}\}$ is a mwg-open cover of $\mathrm{X}$ and since $\mathrm{X}$ is $m_{w g}$-compact, there exists finite number of points, say, $\mathrm{x}_{1}, \mathrm{x}_{2}, \ldots \mathrm{x}_{\mathrm{n}}$ in $\mathrm{X}$ such that $\mathrm{X}=\mathrm{U}\left\{U\left(x_{j}\right): j=\right.$ $1,2, \ldots, n\}$. Thus $\mathrm{Y}=\mathrm{F}(\mathrm{X})=$ $\mathrm{F}\left(\mathrm{U}_{\mathrm{j}=1}^{\mathrm{n}} \mathrm{U}\left(\mathrm{x}_{\mathrm{j}}\right)\right)=\bigcup_{\mathrm{j}=1}^{\mathrm{n}} \mathrm{F}\left(\mathrm{U}\left(\mathrm{x}_{\mathrm{j}}\right)\right) \subset \bigcup_{\mathrm{j}=1}^{\mathrm{n}} \mathrm{V}\left(\mathrm{x}_{\mathrm{j}}\right)=$

$\bigcup_{j=1}^{n} U_{i \in I\left(x_{j}\right)} V_{i}$. This shows that $Y$ is $m_{w g}$-Compact space.

Theorem: 3.20 Let $\mathrm{X}$ be a nonempty set with a minimal structure $m_{X}$. The set of all points $\mathrm{X} \in \mathrm{X}$ at which a multifunction $F:\left(X, m_{X}\right) \rightarrow\left(Y, m_{Y}\right)$ is not upper $m_{w g^{-}}$ irresolute is an identical with the union of $m_{w g}$-frontiers of the upper inverse images of mwg-open sets containing $F(x)$. Proof: Suppose that $F$ is not upper $m_{w g}$-irresolute at $\mathrm{x} \in \mathrm{X}$. Then there exists a mwg-open sets $\mathrm{V}$ of $m_{Y}$ containing $F(x)$ such that $\mathrm{U} \cap\left(\mathrm{X}-F^{+}(\mathrm{V})\right) \neq \Phi$ for every $\mathrm{U} \in m_{X}$ containing x. Therefore, $\mathrm{x} \in m_{w g}-\mathrm{Cl}\left(\mathrm{X}-F^{+}(\mathrm{V})\right)$. On other hand, we have $\mathrm{x} \in F^{+}(\mathrm{V}) \subset m_{w g}-\mathrm{Cl}\left(F^{+}(\mathrm{V})\right)$ and hence $\mathrm{x} \in m_{w g}-\mathrm{Fr}$ $\left(F^{+}(\mathrm{V})\right)$.

Conversely, suppose that that $F$ is upper $m_{w g}$-irresolute at $\mathrm{x}$ $\in \mathrm{X}$. Let $\mathrm{V}$ be a mwg-open set of $m_{Y}$ containing $F(x)$. Then there exist $\mathrm{U} \in m_{X}$ containing $\mathrm{x}$ such that $\mathrm{U} \subset F^{+}(\mathrm{V})$. Hence $\mathrm{x} \in \mathrm{U} \subset m_{w g}-\operatorname{Int}\left(F^{+}(\mathrm{V})\right)$. Therefore, $\mathrm{x} \notin m_{w g}-\mathrm{Fr}\left(F^{+}(\mathrm{V})\right)$ for each mwg-open set $\mathrm{V}$ of $\mathrm{Y}$ containing $F(x)$. this contradicts that $\mathrm{x} \in m_{w g}-\mathrm{Fr}\left(F^{+}(\mathrm{V})\right)$. Thus $F$ is not upper $m_{w g}$-irresolute.

\section{CONCLUSION}

In this paper, we unified a new class of irresolute multifunction such as upper / lower $\mathrm{m}_{\mathrm{wg}}$-irresolute multifunction in Minimal structure. We studied some of its basic characterizations with graph function, separation axioms, compact and connected space and etc. In future, we extend this concept in Bi-minimal space and Ideal minimal space.

\section{ACKNOWLEDGMENT}

The authors are thankful to the reviewers for their valuable comments and suggestions to improve this research paper.

\section{REFERENCE}

[1]. J. Cao and I. L. Reilly, " $\alpha$-Continuous and $\alpha$-Irresolute Multifunctions", Mathematica Bohemica, Vol-121, No. 4, 415 424, 1996.

[2]. M. Mocanu, "On m-Compact spaces", Rendiconti Del Circolo Matematico Di Palermo, Series II, Tomo LIII 1-26, 2005.
[3]. M. E. Abd El-Monsef and A. A. Nasef, "On Multifunctions", Chaos, Solitons \& Fractals, 12, 2387 - 2394, 2001.

[4]. N. Nagaveni and P. Sundaram "On weakly generalized continuous maps, weakly generalized closed maps and weakly generalized irresolute maps in topological spaces", Far East J. of Math. Sci. Vol-6, No. 6, 903 - 912, 1998.

[5]. T. Noiri and V. Popa, "Almost weakly continuous multifunctions", Demonstratio Math., Vol-26, 393 - 380, 1993.

[6]. T. Noiri and V. Popa, "On Upper and Lower M -Continuous Multifunctions", Filomat, Vol-14, 73 - 86, 2000.

[7]. T. Noiri and V. Popa, "On m-quasi Irresolute Multifunctions", Mathematica Moravica, Vol-9, 25 - 41, 2005.

[8]. R. Parimelazhagan, K. Balachandran and N. Nagaveni, "Weakly generalized closed sets in Minimal Structures", Int. J. Contemp. Math. Sciences, Vol-4, No.27, 1335 -1343, 2009.

[9]. V. Popa, "Irresolute Multifunction", Int. J. Math. \& Math. Sci., Vol-13, No.2, 275 - 280, 1990.

[10]. D. Sheeba and N. Nagaveni, “On Minimal Topological Totally Closed Graphs", Annals of pure and applied mathematics, Vol16, No.2, 401 - 411, 2018.

[11]. D. Sheeba and N. Nagaveni, "Multifunction with Topological Closed Graph", Journal of Computer and Mathematical Sciences, Vol-9, No.5, 373 - 383, May 2018.

\section{AUTHOR PROFILE}

Mrs. D. Sheeba ${ }^{1}$ pursed B.Sc., M.Sc., and M.Phil., in Mathematical Science from Nirmala College for women, Coimbatore, Tamil Nadu, India in 2006, 2008 and 2009. She is currently working as Assistant Professor in Department of Mathematics from Coimbatore Institute of Technology, Coimbatore, Tamil Nadu since 2009. She also qualified state level eligibility test (SET) conducted by State Government of TamilNadu in 2017. She has published research papers in Scopus and reputed international journals and it's also available online. Her main research work focuses on General Topology. She has 10 years of teaching experience and 4 years of research experience.

Dr. N. Nagaveni ${ }^{2}$ is currently working as Associate Professor in Department of Mathematics at Coimbatore Institute of Technology in Coimbatore, India. She received her Ph.D degree in the area of Topology in mathematics from Bharathiar University, India in 2000. She is having 27 years of teaching

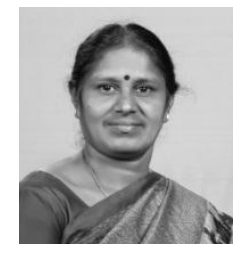
experience. She is having research experience since 1996.Under her guidance 15 M.Phil and $16 \mathrm{Ph} . \mathrm{D}$ candidates have been awarded in different university like Anna University, Bharathiar University, Allagappa University, Mother Teresa University in India in various research area. She is one of the reviewers for few reputed journals. She is also a life member of Indian Society for Technical Education, Kerala Mathematical Association, Indian mathematical society and Member of WSEAS and Indian Science congress. She visited Hong Kong for an international conference conducted by IAENG. She has published eighty five papers in various reputed national and international journals. And she has delivered nearly twenty guest lecturers in different institutions. Her areas of interest are Cloud computing, Data mining, web mining Privacy preservation, Ontology, fuzzy logic, fuzzy system and Topology and its Application. 